\title{
Business Cycles and Recessions in the OECD Area
}

\author{
Riccardo Fiorito* \\ Faculty of Economics, University of Siena, Siena, Italy \\ Email: rfiorito@iol.it
}

Received December 30, 2012; revised January 30, 2013; accepted February 20, 2013

\begin{abstract}
Recessions are less frequent (10\%), more volatile and less persistent than negative business cycles are (50\%). In this article, OECD annual data are used to provide a taxonomy of postwar recessions, showing in particular the frequency, the features and the number of countries involved in major episodes. We shall also implement a simple way for inserting positive (or negative) growth cases into standard business cycle analysis, stressing in particular the importance of recessions for stabilization policies. This applies mostly to fiscal policies that risk otherwise to be more pro-cyclical than normally required.
\end{abstract}

Keywords: Recession; Business Cycle; Stabilization Policies

\section{Introduction}

Recessions differ from negative real GDP cycles mainly because they are less frequent, more volatile and less persistent. Moreover, cyclical fluctuations are stationary, zero-mean, deviations from the long-run level of the economy which is usually approximated by some trend. Conversely, recessions are typically seen as temporary contractions from previous real GDP level and no reference is made to the underlying trend ${ }^{1}$.

In empirical macroeconomics, business cycles are basically treated in two ways: according to the classical or to the growth cycle approach [1,2]. The classical approach was started at the National Bureau of Economic Research (NBER) by Burns and Mitchell [3] and was mainly used for combining short-run forecasting and business cycle evaluation. Since its beginning, the NBER methodology was widely improved but is still based on finding - and possibly anticipating - the expansion and contraction phases in the US economy.

This is essentially done evaluating the peaks and the troughs of the economy using a variety of indicators and then defining a recession as the phase between a peak and next trough. This approach focuses on measuring (anticipating) contraction and expansion phases that refer to indicators for the US activity level, then classified according to an official NBER chronology [4]. Despite the wide use of several time-series improvements, the chronology choice was and still is basically judgemental,

\footnotetext{
*Editorial help and comments from anonymous referees are acknowledged without implication.

${ }^{1}$ To avoid occasional episodes, for quarterly data Shiskin [9] suggested that a recession needs at least two successive output contractions.
}

though certainly not arbitrary given the soundness of the techniques and the prestige of the evaluation committee.

In any case, even the most updated NBER methodology is not interested in evaluating business cycles in the way they are defined in standard macroeconomics, i.e. as stationary persistent and symmetric deviations from a stochastic trend which approximates the underlying growth process, as in Lucas [5]. This definition updates and makes more precise the traditional growth cycle approach which is generally used to obtain zero-mean cycles from the residuals of a trend estimate [6]. By construction, negative (and positive) cycles are equally likely, though revealing a persistence in the data which reflects the duration of business cycle shocks. These features allow researchers to evaluate how the cyclical components can be related to possible sources through co-movements that do not need to be contemporaneous, being also possibly leading or lagging as shown by Kydland and Prescott [7] in their celebrated stylized fact study.

For convenience, I display in the following Graph 1 the simplest version of the growth-cycle approach where a trend line is used to obtain the cyclical components of the economy. The graph describes the positive (ABC) and the negative cycle areas (CDE) that for logged data also correspond to positive or negative output gaps $\left(y_{t}-\right.$ $\left.y^{*}\right)$, so commonly used in devising stabilization policies [8].

Let us denote by $y_{t}$ and $y^{*}{ }_{t}$ actual and equilibrium real GDP log-levels and by $d_{t}$ and $d^{*}{ }_{t}$ their corresponding growth rates, respectively. Further, let us introduce beside the output gap (YGAP $=y_{t}-y^{*}{ }_{t}$ ) a growth gap measure (DGAP $=d_{t}-d^{*}$ ), given by the difference between actual and equilibrium growth rates. This simple 


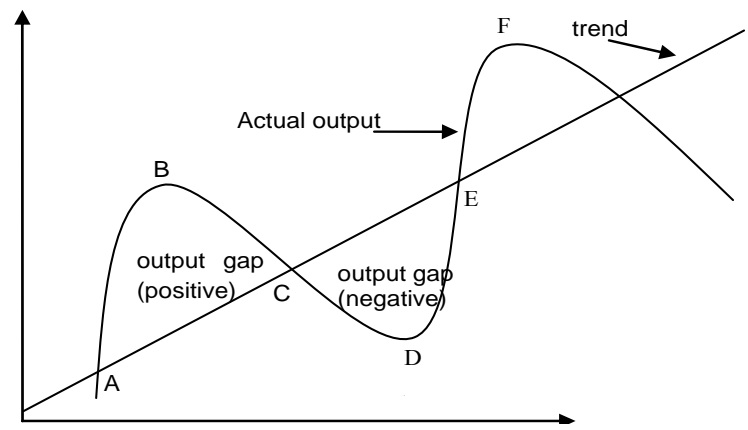

Graph 1. Textbook business cycle phases.

device allows us to use Graph 1 for classifying business cycles in four rather than in two standard states:

Phase $1=\mathrm{AB}: d_{t}>d^{*}{ }_{t}$ and $y_{t}>y^{*}{ }_{t} \rightarrow \rho($ DGAP, YGAP) $>0$,

Phase $2=$ BC: $d_{t}<d^{*}{ }_{t}$ and $y_{t}>y^{*}{ }_{t} \rightarrow \rho($ DGAP, YGAP) $<0$,

Phase $3=\mathrm{CD}: d_{t}<d^{*}{ }_{t}$ and $y_{t}<y^{*}{ }_{t} \rightarrow \rho(\mathrm{DGAP}, \mathrm{YGAP})$ $>0$,

Phase $4=$ DE: $d_{t}>d^{*}{ }_{t}$ and $y_{t}<y^{*} \rightarrow \rho($ DGAP, YGAP $)$ $<0$,

where the term $\rho$ (DGAP, YGAP) denotes the expected correlation between the two gaps.
However simple, this classification helps to make explicit that recessions $\left(d_{t}<0<d^{*}\right)$ occur in phases BC and $\mathrm{CD}$ and can be easily inserted into business cycle analysis once it is recognized that in the $\mathrm{BC}$ part recessions coexist with a positive output gap to be faced by contractionary stabilization. Conversely, in the DE portion a negative cycle coexists with a growth of the economy exceeding the equilibrium rate, though stabilization policies should be still oriented in an expansionary way.

Given the obvious limits of stabilization policies in both $\mathrm{BC}$ and $\mathrm{DE}$ cases, it seems useful comparing the textbook graph with actual data to see if the above-mentioned states are equally likely as implied by the textbook graphs.

\section{What the Data Say Instead}

The phase statistics reported in Table 1 for annual OECD data are quite different from those implied in Graph 1 and the sample seems long enough to provide a non-episodic evidence of the main business cycle patterns. Since there are no important national differences, the average phase distribution reported at the top of the table clearly shows that the four phases are not equally likely.

The major result in Table $\mathbf{1}$ certainly is not a surprise

Table 1. Business cycle phases and recessions in selected OECD countries.

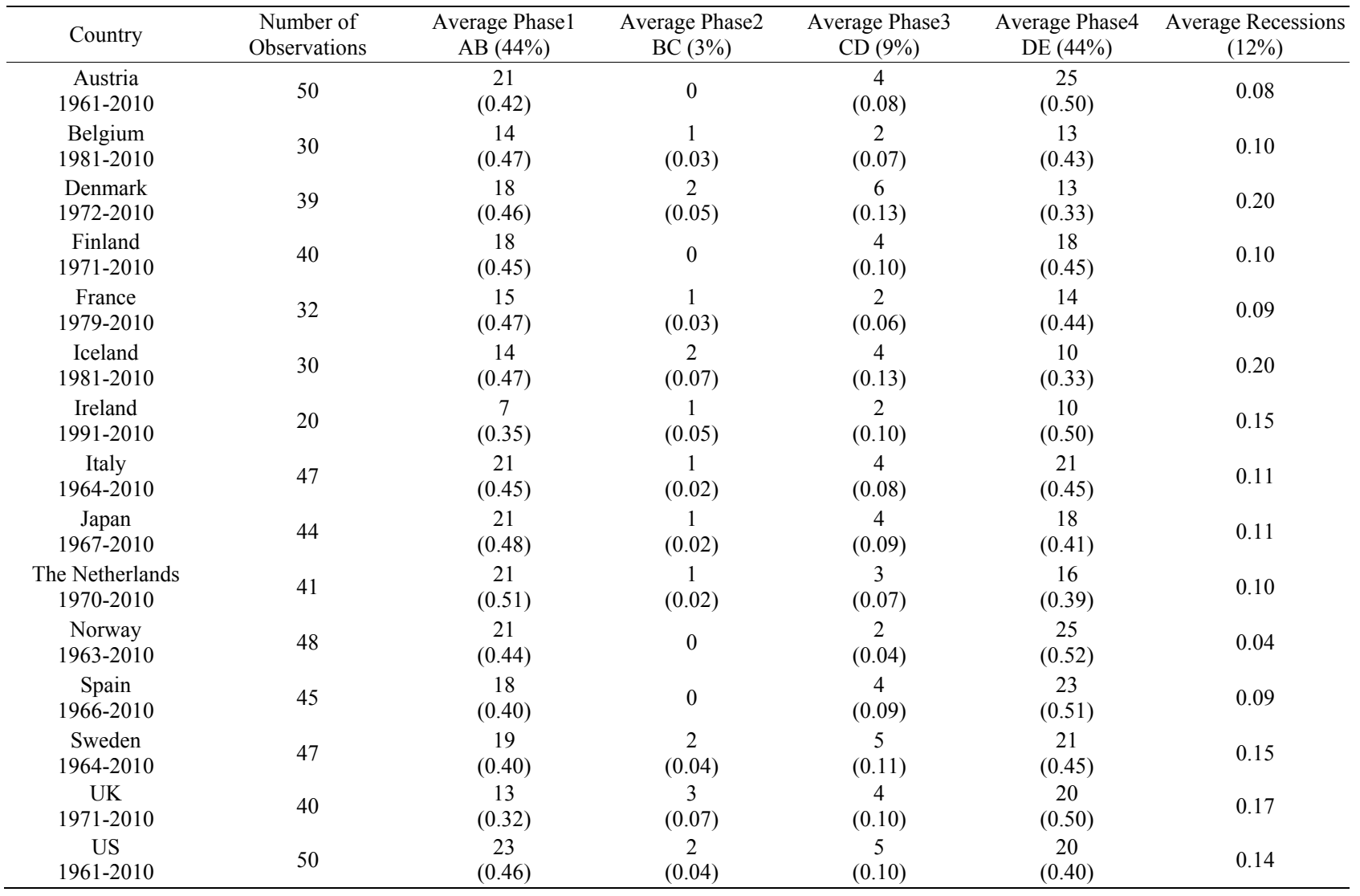

Legend: OECD, Economic Outlook Database. Numbers in parenthesis denote the percentage frequency of each phase. 
since expansion phases $(\mathrm{AB}+\mathrm{DE})$ dominate $(88 \%)$ the much less frequent $(12 \%)$ recession cases $(\mathrm{BC}+\mathrm{CD})$ as modern economies typically do: after all, this is why there is normally growth!

It is also noteworthy that the $\mathrm{AB}$ and $\mathrm{DE}$ growth phases have the same frequency (44\%) despite they belong to different business cycle positions. Recession phases differ instead since the BC portion (3\%) occurs much less than the $\mathrm{CD}$ phase does $(9 \%)$, suggesting that most GDP contractions happen during negative rather than positive cycles. Overall, in the full OECD sample (Table 2), annual recessions involve about the $10 \%$ of cases which is not too different from Table 1 evidence which is confined for convenience to a subset of countries.

Strong recessions - defined here as real GDP contractions of at least $2 \%$ (see Table 2) - are about the $4 \%$ of cases.

Excluding last crisis, recessions and strong recessions are $8.2 \%$ and $2.5 \%$ of cases, respectively. Finally, strong recovery episodes (DE: $d_{t}>d^{*}{ }_{t}$ ) still belong to negative output gap cases when fiscal expansion is recommended. Since this phase frequency much exceeds the BC phase, it should not be surprising that, even among developed countries, government spending is much less counter-cyclical $[10,11]$ than typically assumed.

Table 2 reports for all the OECD countries the recession episodes until the most recent 2012 data. The reported information allows us to see how many countries were involved in the same year by a recession and how long the relevant episode was lasting in each case.

Ignoring idiosyncratic cases, usually prevailing at the beginning of the sample when the OECD economies were much less integrated, there are four major recession (Table 3) episodes affecting a large number of countries in the same year:

1) $1974-1975 \rightarrow$ first oil shock aftermath (1973) $\rightarrow 12$ countries over 26.

2) Early 80s: a mixture between the effects of the 2 nd oil shock (1979) and a regional, Northern European, crisis involving 8 countries in 1981 and 6 in 1982.

3) Early 90s crisis: EMS fall $\rightarrow$ Italian Lira, Spanish Peseta and UK Pound devaluation $\rightarrow 12$ countries.

4) Last crisis peak in 2009: 27 OECD countries over 30 have been involved!

Table 2. Recessions in the OECD (1961-2012).

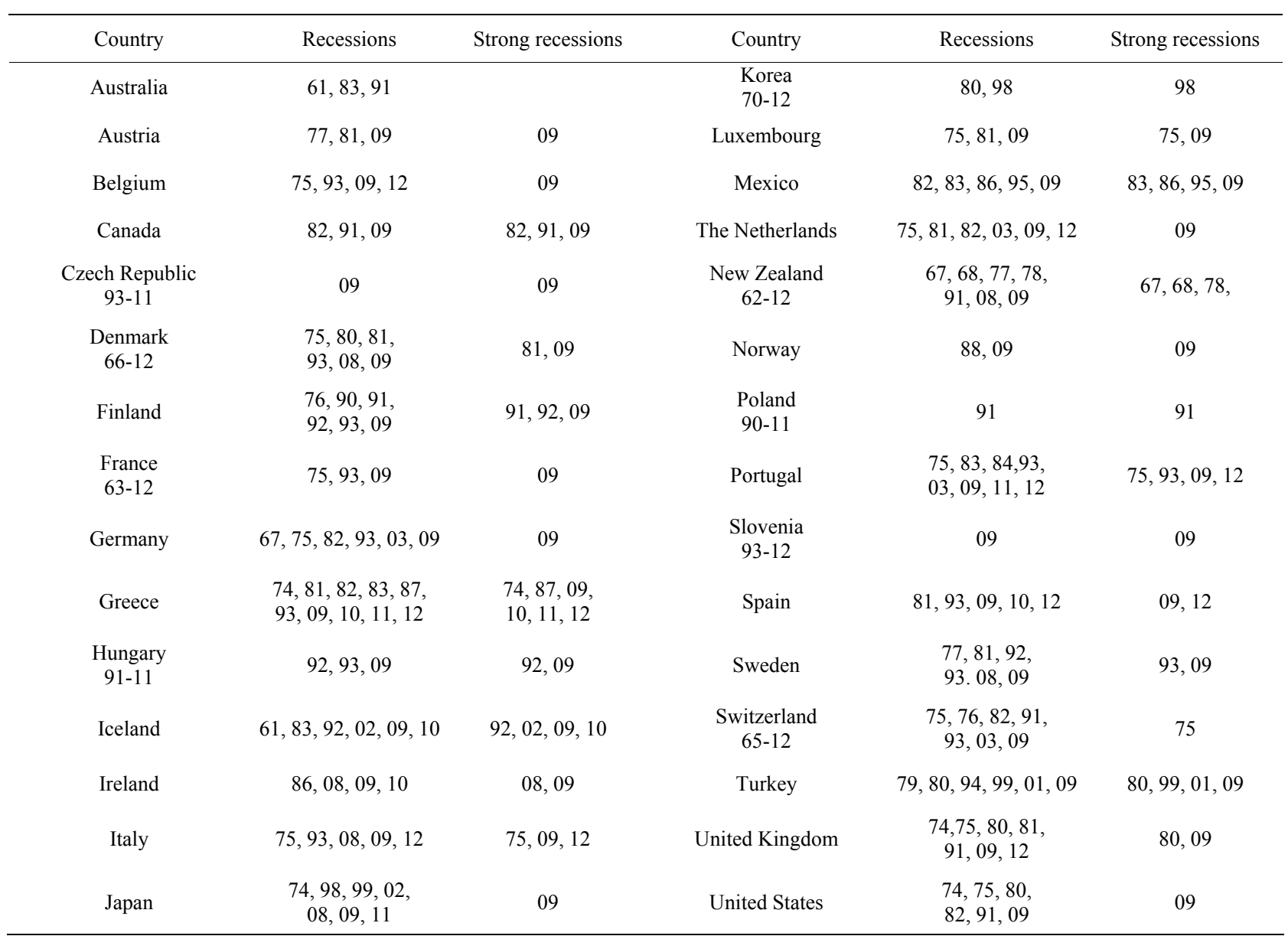

Legend: OECD, Economic Outlook Database. Strong recessions denote at least a $\%$ real GDP fall. 
Table 3. Number of countries involved in recession episodes.

\begin{tabular}{cccccc}
\hline Year & Recession & Strong recessions & Year & Recession & Strong recessions \\
\hline 1974 & $4 / 26$ & $1 / 26$ & 1992 & $4 / 28$ & $3 / 28$ \\
1975 & $12 / 26$ & $4 / 26$ & 1993 & $12 / 30$ & $2 / 30$ \\
1981 & $8 / 26$ & $1 / 26$ & 2003 & $4 / 30$ & $1 / 30$ \\
1982 & $6 / 26$ & & 2008 & $6 / 30$ & $23 / 30$ \\
1983 & $5 / 26$ & $1 / 26$ & 2009 & $27 / 30$ & $2 / 34$ \\
1991 & $7 / 28$ & $3 / 28$ & 2010 & $4 / 34$ & $2 / 34$ \\
2011 & $3 / 34$ & $1 / 34$ & 2012 & $4 / 34$ & \\
\hline
\end{tabular}

Source: See Table 1. Asia 1997-1998 crisis for non-OECD countries is not accounted for.

Finally, it should also be noticed that the 2009 crisis differs from the others because this is the first case where virtually all OECD countries were facing a nominal recession $^{2}$ : A fact that was unconceivable in all previous episodes where high inflation was widely exceeding real GDP fall.

Length: Most recessions last about 1 - 2 years and current Greek contraction - including the 2013 OECD forecast [12] - is a dramatic exception. Other long recessions include still Greece (1981-1983), Finland (1990-1993) and Ireland in the last 2008-2010 crisis. Another novelty found in last crisis is the so called double dip recession, i.e. an output contraction following a scant recovery from a previous recession as the 2012 data show for Portugal, Italy and Spain: three countries facing with Greece a new nominal recession, also increasing the government debtto-GDP ratio.

Using quarterly data for the G-7 countries and comparing-whenever possible-Table 4 with the annual data in Table $\mathbf{1}^{3}$, we see that contractions are more numerous than recessions defined in terms of the two-quarters rule. Recession frequency is about the same than the one found with the annual data, showing that in a shorter sample (more affected by last international crisis) recession episodes involve something between the $10 \%$ and the $20 \%$ of cases, i.e. much less than the $50 \%$ assumed by the negative output gap measure.

The quarterly G-7 evidence shows in Table 4 that the last crisis was, with the exception of Canada, also the recession lasting more. Finally, it is also interesting to note that the NBER chronology for the US finds a peak-totrough interval which about coincides (2007.4-2009.2) with the contraction reported here using real GDP percentage changes.

\footnotetext{
${ }^{2}$ Actually, Japan only had a nominal recession between 2001 and 2003. Conversely, in the enlarged OECD area, only Australia, Chile, Israel, Poland and Turkey were immune from nominal recession in 2009. ${ }^{3}$ The quarterly sample is smaller both in terms of the included countries and of the time-series span.
}

\section{Growth and Cycles: A Possible Reconciliation}

Let both actual $(y)$ and potential output $\left(y^{*}\right)$ be a unit root, random walk, process:

$$
\begin{gathered}
y_{t}=d_{t}+y_{t-1} \\
d_{t}=d+e_{t}, e_{t} \sim \operatorname{iid}\left(0, \sigma^{2}\right) \\
y_{t}{ }^{*}=d_{t}{ }^{*}+y^{*}{ }_{t-1} \\
d_{t}^{*}=d+e_{t}^{*}, e_{t}^{*} \sim \operatorname{iid}\left(0, \sigma^{2 *}\right), \sigma^{* 2}<\sigma^{2}<\infty
\end{gathered}
$$

where $d$ is the common drift term and where $e_{t}$ and $e^{*}{ }_{t}$ are white noise shocks driving actual and potential growth, respectively. As before, variables are in logs and, after solving for Equations (1)-(4), cycles $\left(c_{t}=y_{t}-y^{*}\right)$ can be expressed as the sum of current growth gap $\left(d_{t}-d^{*}{ }_{t}\right)$ and of the previous period cycle:

$$
\begin{aligned}
c_{t} & =\left(d_{t}-d_{t}^{*}\right)+\left(y_{t-1}-y_{t-1}^{*}\right) \\
& =\left(d_{t}-d_{t}^{*}\right)+c_{t-1}, d_{t}^{*}>0,
\end{aligned}
$$

where $d_{t}^{*}$ can be obtained from the smoothly changing growth rate of the HP-filtered real GDP variable.

Equation (5) has several implications that we also discussed in $[13,14]$ :

- Recessions $\left(d_{t}<0\right)$ are more volatile than normal GDP changes since in this case the growth gap $\left(d_{t}-\right.$ $\left.d^{*}{ }_{t}\right)$ variance must be necessarily bigger, assuming that potential growth rate $\left(d^{*}\right)$ is always positive.

- Business cycle changes correspond to the growth gap since: $\Delta c_{t}=\left(d_{t}-d_{t}^{*}\right)$.

- Finally, evaluating business cycle patterns as in the stylized facts approach, it is possible to interpret the persistence and volatility of each stationary cyclical component as also reflecting the growth gap component and the role of recessions.

Some of these properties can be visually inspected in the following G-7 Graphs where we report for each coun- 
Table 4. G-7 recessions frequency and length for quarterly data.

\begin{tabular}{cccccc}
\hline Country & Sample & Number of observations & Number of contractions & Number of recessions & Longest recession \\
\hline Canada & $1980.1-2012.3$ & 130 & $23(0.18)$ & $17(0.13)$ & $1990.1-1990.4$ \\
United States & $1980.1-2012.3$ & 130 & $17(0.13)$ & $12(0.09)$ & $2008.1-2009.2$ \\
Japan & $1980.1-2012.3$ & 130 & $36(0.28)$ & $15(0.12)$ & $2008.2-2009.2$ \\
UK & $1980.1-2012.3$ & 130 & $22(0.17)$ & $16(0.12)$ & $2008.2-2009.3$ \\
Germany & $1991.1-2012.3$ & 86 & $22(0.26)$ & $13(0.15)$ & $2008.2-2009.1$ \\
France & $1980.1-2012.3$ & 130 & $17(0.13)$ & $10(0.08)$ & $2008.2-2009.1$ \\
Italy & $1981.1-2012.3$ & 130 & $34(0.26)$ & $23(0.18)$ & $2011.4-2012.3$ \\
\hline
\end{tabular}

Source: OECD, Economic Outlook Database (seasonally adjusted real GDP data, November 2012).

try the business cycle data obtained using the HP filter ${ }^{4}$ along with the changes in the actual and potential real GDP growth. In all cases, the most recent data make visible last recession amplitude and its relation with large cyclical fluctuations.

In several cases, the potential growth rate tends to decrease with respect to the earlier sample: this clearly appears in the Japan "lost decade" (Figure 1) but also in France (Figure 2) and even more (Figure 3) in Italy. Comparing the zero-mean cyclical component with actual growth rates, analogies (Figures $\mathbf{4}$ and 5) and differences are visible and even visual inspection confirms the higher volatility in the few recession times and in the last crisis in particular (Figures 6 and 7).

\section{Conclusions}

The reported data provide a first comparative evidence for the OECD countries, stressing the novelty and the depth of last international crisis. In this respect, the necessity of disentangling recessions from ordinary business cycles is not made here to abandon cyclical analysis but is used instead to show that cyclical analysis can also account for recessions, however infrequent they are.

The motivation for stressing this point is twofold: the first deals with the benefit of using the stylized facts approach for including growth considerations that apply also to negative growth cases. The second point rather aims at suggesting that traditional stabilization policiesespecially fiscal ones - need a reconsideration in recession times as shown by the IMF [16] and, especially, by Auerbach and Gorodnicenko [17]. This happens because confining fiscal policy to automatic responses can make government spending too high when the economy already grows and too low when the economy contracts, though recessions are generally shorter and more volatile than standard cycles are.

${ }^{4}$ Following Ravn and Uhlig [15], the smoothing parameter for annual data is 6.25. Using different values, however, results do not change remarkably.

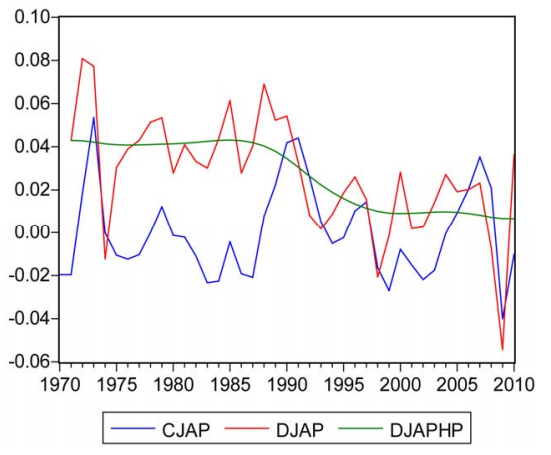

Figure 1. Japan: Business cycles (CJAP), actual (DJAP) and potential (DJAPHP) rates of growth.

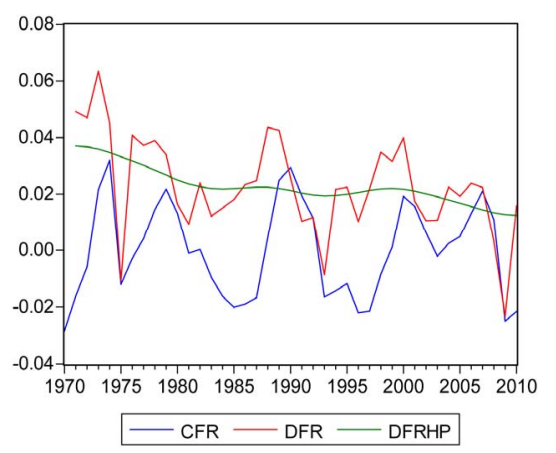

Figure 2. France: Business cycles (CFR), actual (DFR) and potential (DFRHP) growth.

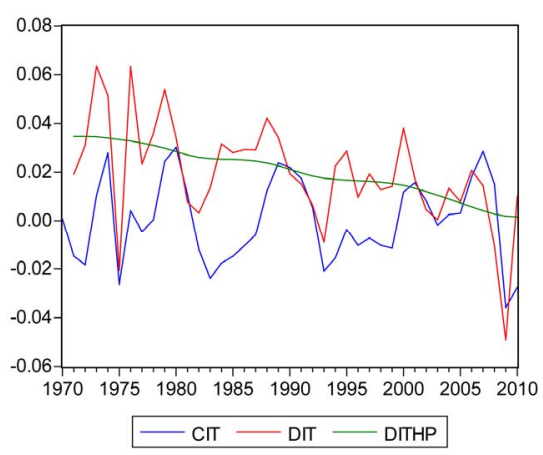

Figure 3. Italy: Business cycles (CIT), actual (DIT) and potential (DITHP) growth. 


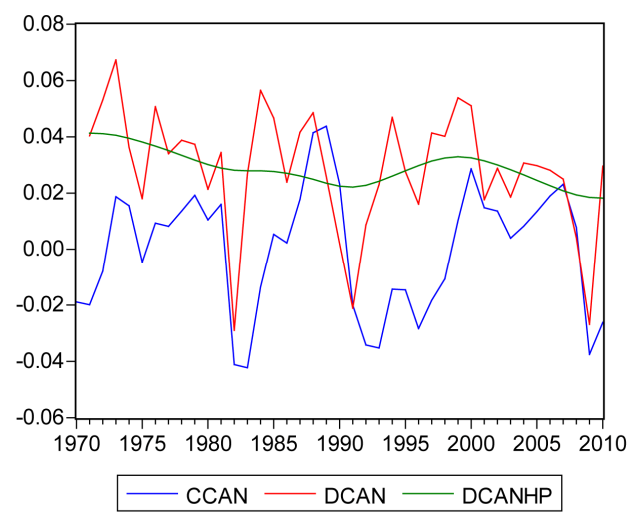

Figure 4. Canada: Business cycles (CCAN), actual (DCAN) and potential (DCANHP) growth.

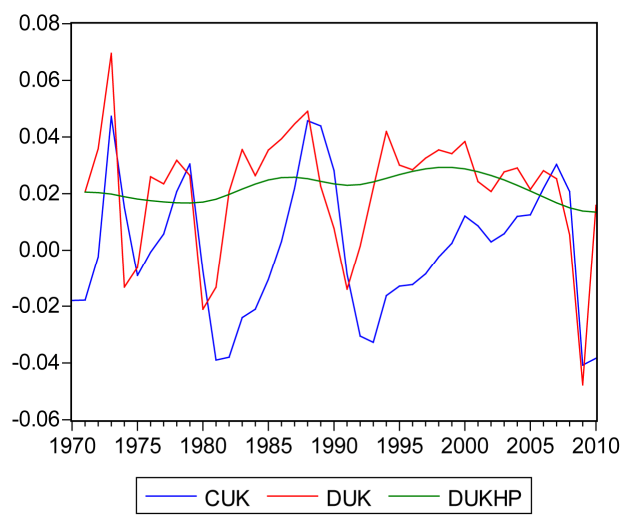

Figure 6. United Kingdom: Business cycles (CUK), actual (DUK) and potential (DUKHP).

\section{REFERENCES}

[1] J. Stock and M. Watson, Eds., "Business Cycles, Indicators and Forecasting," University of Chicago Press, Chicago, 1993.

doi:10.7208/chicago/9780226774749.001.0001

[2] F. Canova, "Methods for Applied Macroeconomic Research," Princeton University Press, Princeton, 2007.

[3] A. Burns and W. Mitchell, "Measuring Business Cycle," National Bureau of Economic Research, New York, 1946.

[4] NBER, "The NBER's Business Cycle Dating Committee," 20 September 2010.

[5] R. E. Lucas, "Understanding Business Cycles," In: Carnegie-Rochester Series on Public Policies, North Holland, 1977, pp. 7-29.

[6] C. Nelson, "Trend/Cycle Decomposition," In: S. Durlauf and L. E. Blume, Eds., Macroeconometrics and TimeSeries Analysis, Palgrave Macmillan, Basingstoke, 2010, pp. 343-346.

[7] F. Kydland and E. Prescott, "Business Cycles: Real Facts and a Monetary Myth," Federal Reserve Bank of Minneapolis Quarterly Review, Vol. 14, No. 2, 1990, pp. 3-18.

[8] O. J. Blanchard, "Suggestions for a New Set of Fiscal Indicators," OECD WP \# 79, 1990.

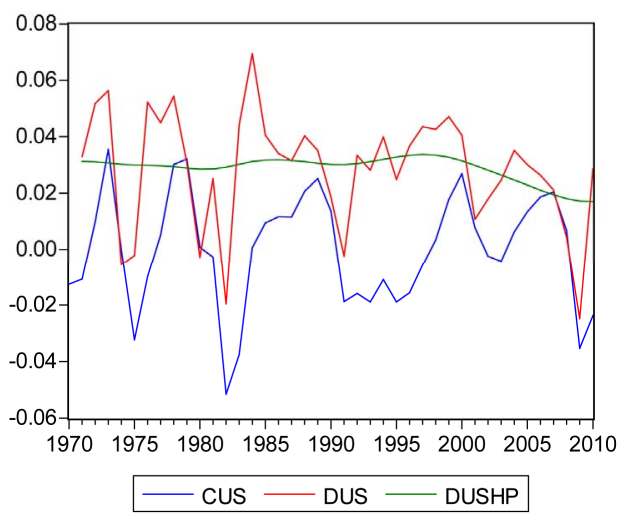

Figure 5. United States: Business cycles (CUS), actual (DUS) and potential (DUSHP) growth.

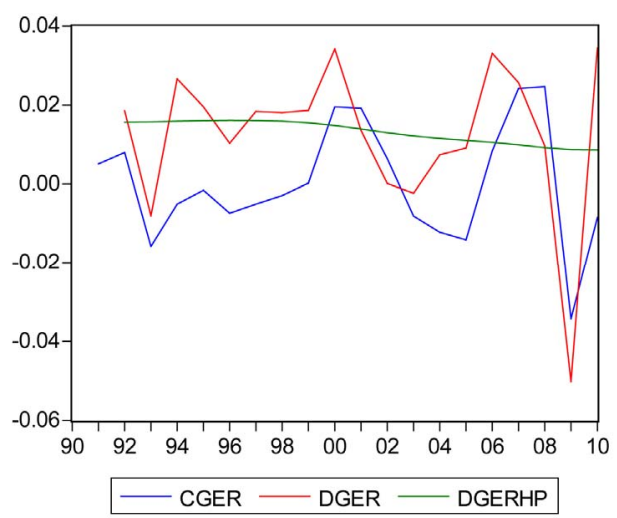

Figure 7. Germany: Business cycles (CGER), actual (DGER) and potential (DGERHP) growth.

[9] J. Shiskin, "The Changing Business Cycle," New York Times, 12 December 1974.

[10] R. Fiorito, "Stylized Facts of Government Finance in the G-7,” IMF Working Paper 97/142, 1997.

[11] P. R. Lane, "The Cyclical Behaviour of Fiscal Policy: Evidence from the OECD," Journal of Public Economics, Vol. 87, No. 12, 2003, pp. 2661-2675. doi:10.1016/S0047-2727(02)00075-0

[12] OECD, "Economic Outlook," Paris, November 2012.

[13] R. Fiorito, "Recessioni, Cicli e Politica Fiscale," Rivista di Politica Economica, Vol. 3, 2012, pp. 141-164.

[14] F. Coricelli and R. Fiorito, "Output Gap, Recessions and Fiscal Discretion," Case Conference, Warsaw, November 2009.

[15] O. Ravn and H. Uhlig, "On Adjusting the HP Filter for the Frequency of Observations," Review of Economics and Statistics, Vol. 84, No. 3, 2002, pp. 71-75.

[16] IMF, "Will It Hurt? Macroeconomic Effects of Fiscal Consolidation," In: World Economic Outlook, 2010, pp. 93-124.

[17] A. J. Auerbach and Y. Gorodnicenko, "Measuring the Output Responses to Fiscal Policy," American Economic Journal: Economic Policy, Vol. 4, No. 2, 2012, pp. 1-27. doi:10.1257/pol.4.2.1 